\title{
Morphological irregularities: why, what, where, who and when?
}

\author{
Marijke De Belder \\ Carl von Ossietzky Universität Oldenburg \\ Marijke.de.belder@uni-oldenburg.de
}

How to cite: De Belder, Marijke. 2021. Morphological irregularities: why, what, where, who and when? Isogloss. Open Journal of Romance Linguistics 7,15:1-11.

\section{Introduction}

I was asked to write a reply on the following question: "Are (Romance) morphological "irregularities" to be analysed as exceptions or should we try and find some sort of regularity?" and to take Michal Starke's 2020 NELS talk as a starting point. Before I raise some considerations, I want to be explicit about my core position regarding the central question just mentioned.

I believe that anyone who is somewhat familiar with my work on Dutch morphology, will understand that I feel outmost sympathy to any morphologist looking for regular patterns in what seems to be an irregular empirical domain. In fact, I have dedicated many sweet hours of my own life to precisely this goal (e.g. De Belder 2020, to appear). I can only express my deepest appreciation for the NELS talk by Michal Starke in which he proposed an impressive analysis of French morphology, which combines strong empirical adequacy with minimal theoretical assumptions. The software tool he presented at the end further illustrates how serious the nanosyntactic project is engaged with data and it promises to advance morphological analyses. In reply to the question by Julie 
Doner it further became clear that the talk is framed in a bigger, ambitious and promising project, which I am curious to learn more about in the future.

Having stressed that I believe I am on the same side as Michal Starke when it comes to the enterprise of looking for general patterns that allow us to formulate principles that govern the interfaces, I nevertheless would like to raise some questions which I think are relevant to such a project.

\section{Why are we worried about irregularities and what are they?}

The very first sentence of Michal Starke's slide show states that there is no irregular morphology. I therefore assume this claim is important to him and I assume he wants to communicate to the field that we should take this claim seriously when doing morphology. In this respect, I very much regret that he does not discuss why we should take this claim so seriously. To state the obvious, any generative linguist will deny that language is learned behaviour or nothing but memorised knowledge and we tend to favour rules and patterns over memory as an explanation. But there is still a difference between stressing the general rulebased nature of the linguistic competence and the claim that there is no irregular morphology at all.

So why does Starke so strongly deny irregularity as a possibility? Is his claim to be interpreted as a methodological guideline, a warning about good scientific practice? His final sentence could be interpreted as such: "Impossible only means that you haven't found the solution yet." It may warn us against relying on hasty brute force solutions such as relying on memory whenever we fail to understand linguistic data. Or is his claim that no irregularity exists in morphology a serious claim about the human linguistic competence? Does he assume it is simply impossible for the syntax-lexicon interface to store and process irregularities? The algorithmic nature of nanosyntax favours this interpretation. Indeed, if even a software tool is supposed to be able to process inflectional patterns, there is no room for irregular morphology in such a framework.

Now, we know that humans make use of extraordinary memory capacities when processing language. The size of our lexicons and the way lemmas are connected is impressive. We memorise around 50000 to 80000 words per language, we memorise the lexicons of several languages, we have stored semantic connections and connections between the same lemmas of different languages (Aitchison 2012). We have memorised idioms, registers, etc. Surely, our huge and flexible lexical memory can host a handful of morphological irregularities at almost no cost. Then why is it so important to demonstrate irregularities are not an option?

Perhaps the core of the issue is that it is unclear to me what exactly is meant by irregularities in Starke's talk. Demonstrating that irregularities are not an option very much relies on a definition of what should be called irregular. It would, for example, not be too far-fetched to call the French form [se], sais, irregular. I understand that Starke successfully derives it in a principled manner, but he does assume that something quite unexpected is present in the lexicon. It is a form, that unlike the other forms of the verb, realises the entire verbal functional 
tree. It is a form that a speaker will only realise successfully if they memorised the appropriate form, it cannot be formed compositionally. Its unexpected form is not intrinsically motivated by independent principles. In other words, it is irregular to me. Do not be mistaken, the irregularity is there in the nanosyntactic approach as well, but is masked as a lexical item. The irregularity is first stored in the lexicon as a lexical item and then used algorithmically by the insertion mechanism. There is no escaping storing the unexpected when doing morphology.

I guess that the 'irregular' in nanosyntax is thus not a form that fails to realise transparently the functional heads that are realised by other forms in the language, but a form that cannot be derived by the nanosyntactic algorithm, a form that would cause an error in the software. Is Starke's claim that no irregularity exists then to be interpreted as 'all morphology can be derived algorithmically' or even 'no ABA patterns!'? Or, given that he refers to readjustment rules, perhaps he intends to claim that there is no role for morphophonological rules in linguistic derivations? If it can be fleshed out exactly what the claim is, it would also be easier to determine whether French inflection is the appropriate empirical domain to substantiate it. I come back to this in more detail in the following two sections.

\section{Where to look for irregularities?}

Before I phrase the following criticism, let me stress the quality of the nanosyntactic analyses. The consistency, coherence and empirical adequacy of the analysis in the talk and the projects mentioned during the talk (Caha's (2009) case project, De Clercq's (2013) analysis of negation, Caha, De Clerq and Vanden Wyngaerd's (2019) project on comparatives, etc.) is nothing but impressive. That being said, if I had to choose empirical domains to show that an algorithmic approach to the syntax-lexicon interface could be successful, I would probably have picked empirical domains similar to the ones just mentioned. During the talk, Starke refers to the French verbal inflection as an instance of 'usual suspects of chaotic morphology'. Even though I fully acknowledge the challenging nature of such a domain, calling it a usual suspect of chaotic morphology is an exaggeration. If I had to show that morphology is pretty regular, I would look precisely at inflection. In contrast, there are two domains I would wisely stay far away from. Firstly, I would avoid lemma-creating morphology, i.e. derivation and compounding. Secondly, I would stay clear of domains where the lexicon and syntax also seem to interface with phonology (i.e. morpho-phonology). These domains are the true suspects of irregularity. Below I discuss these issues in somewhat more depth.

Admittedly, I find it hard to imagine what an analysis of a compound or a derivation (in the morphological sense of the word, i.e. lemma-creating affixation) would look like in nanosyntax. Nanosyntax has engaged successfully with empirical domains that can be understood as forming 'paradigms' (in the nontheoretical sense of the word) which show famous AB-patterns and cartographic sequences of functional heads. As such, the compound and the derivation in nanosyntax are terra incognita to me. How would the syntax-lexicon interface 
operate? What is predicted for these empirical domains? Do we expect that an algorithm can derive them?

The core empirical issue with compounding and derivation is that the existing words are inherited as the results of various historical processes with various degrees of productivity through the centuries. As a result, even though many insightful generalisations can be formulated for these domains, one quickly faces the unavoidable conclusion that information is stored. If in my Dutch lexicon I have two competing forms to refer to a woman from Friesland, i.e. Friezin and Friese, then that is due to the fact that the result of the now improductive rule to form words referring to women (attach the affix -in to a root referring to an animate being) is stored in my lexicon and co-exists with the result of the now productive rule (add a schwa to a root referring to an animate being: Friese). The fact that Friezin is an existing, lexicalised stored form and Drenthin (intended: a woman from Drenthe) is not an existing word, is also stored information. More generally: I have stored morphologically complex lexical items and lexical gaps.

My Dutch mental lexicon has also stored the results of phonological rules that applied in earlier days. The fact that the adverb corresponding to the noun dag 'day' is daags 'daily' shows a tense vowel, whereas the noun shows a lax vowel is fully explainable. The stem of the adverb had an open syllable in Early Middle Dutch (daghes) and was therefore subject to the then applicable rule of vowel lengthening (Prokosch 1939; Lahiri \& Dresher 1999, a.o.). The morphological complexity of the form is still transparent to the native speaker. In contemporary Dutch dag still has an allomorph with a tense vowel and there are plenty of adverbs formed by the suffix $-s$ (Corver 2017). However, the selection of this specific allomorph does not follow from any rule in contemporary Dutch. What else is there to say in the $21^{\text {st }}$ century then that the adverb is lexically stored with the tense vowel?

Consider yet another example. The complement of the suffix -schap in Dutch is usually to be interpreted nominally: moederschap 'motherhood', koningschap 'kingship'. But some exceptional forms are stored for which the complement is to be interpreted adjectivally: zwangerschap 'pregnancy', dronkenschap 'drunkenness'. The unexpected forms with an adjective plus -schap are stored exceptions to the more general rule that the complement of -schap is nominal.

The above examples do not illustrate that Dutch morphologists failed to look for generalisations, rules or patterns. It is precisely because we have looked so thoroughly and because we have documented the language so precisely that we are aware of the examples that will escape all non-lexical generalisations. Surely, I am not pointing out anything new here. Examples such as the ones given above are well-known. It is commonplace knowledge that compounding and derivation are domains filled to the rim with stored forms and accidental gaps. It is therefore difficult to me to accept the conclusion that all morphology is regular when the most irregular domains of morphology are simply left out of the discussion.

The morphologist looking for a challenge should not rest once compounding and derivation are conquered. Around the corner an even worse empirical domain is waiting for them. If one thinks the lexicon-syntax interface has nothing unexpected to offer, I propose to look at the phonology-syntax 
interface. The already mentioned distribution of stem allomorphs with lax and tense vowels in Dutch inflection and derivation is an infamous example. Van der Hulst (1985) already pointed out that many examples can and should be captured by referring to the Dutch rules of syllabification. Booij (1999: 88) points to examples that escape the phonological generalisation. De Belder (2020) is a systematic discussion of which alternations can be captured phonologically and which ones escape the rules of $21^{\text {st }}$ century Dutch. The exceptional forms did not fall out of the blue sky: we understand when and how they were formed according to past rules in older versions of Dutch, as I explained for the adverb daags 'daily' above. Again, the fact that Dutch phonologists and morphologists are aware of the problems within this empirical domain does not illustrate the fact that we did not attempt to find generalisations. The field engaged very seriously with this project and we can conclude with confidence that there are lexically stored irregularities in this domain.

If even the syntax-phonology is not challenging enough, try empirical domains which show a simultaneous interplay between syntax, phonology and the lexicon. I have written about such a domain (De Belder to appear): there are epenthetic consonants of which the occurrence depends on a specific morphosyntactic context, a specific affix and a specific phonological context (see also Zygis' 2010 typology on epenthetic consonants). The epenthetic consonant -s- will occur in Dutch after a stem if three conditions are fulfilled simultaneously: (i) the stems ends in a velar consonant (a phonological requirement), (ii) the diminutive affix - $k e$ (and not -tje) is used (a lexical requirement) and (iii) the diminutive affix truly realises a diminutive functional head (and not a honorific head) (a syntactic requirement). A successful approach to morphology should be able to model such facts.

Further examples of analyses that include the morphology-phonology interface, from various frameworks, are McCarthy and Prince (1993), Booij (1998), Yu (2003), Paster (2006), Bye (2007), Wolf (2008), Bye and Svenonius (2012), Embick (2010), Nevins (2010), Bonet and Harbour (2012), amongst many others, see in particular also Trommer (2012) for a thematic bundle with many relevant contributions. These are the empirical domains to address when one would like to substantiate any claim on morpho-phonological irregularities. Unless such work is addressed by nanosyntax, let me say that I feel it is yet to be shown that all morphology is regular.

I would like to close this section with a final consideration. If a contemporary article on Distributed Morphology looks a bit unruly, it is often an article that fully engages with phonology and semantics. If one strictly models the syntax-lexicon interface, one can hope to achieve a principled and clean solution, even though the undertaking is certainly challenging enough. Morphologists typically start to list exceptions when on top of the syntax-lexicon interface, they also try to model the other interfaces. I signal this to make sure apples are compared to apples: the economy of a nanosyntactic approach should be compared to the economy of a competing approach that strictly models the syntax-lexicon interface. 


\section{Who has been ignoring regular patterns and when were they doing so?}

I would like to comment on the style figure of the straw man in the nanosyntactic rhetorics. It is present in Starke's talk and it is not the first time he uses this style figure in his work. This straw man is vaguely given a face that reminds us of last century Distributed Morphology, as terms as 'readjustment rules' are associated to it. However, the straw man is never given a name. We never learn which analysis of which data by which linguist is critiqued. We never learn why the opponent formulated an idea such as a readjustment rule. Opposing views are cited in the talk as 'people' ("people see mismatches") or 'they' ("they end up concluding"). Surely, if French verbal inflection is a 'usual suspect' of chaotic morphology, it should be possible to give a reference of an opposing analysis and to discuss the flaws of the opposing analysis in detail? I believe that the use of this style figure hampers the scientific dialogue.

A true dialogue would benefit the field tremendously. For example, Smith et al. (2018:13) propose a morphologically conditioned phonological rule for Nepali pronouns, to argue that these pronouns follow an AAA-pattern rather than a ABA-pattern. (I have pointed out above that as soon as one acknowledges that the lexicon not only interfaces with syntax, but also with phonology, one does encounter data that are more difficult to model.) We could discuss whether we call morphologically conditioned phonological rules readjustment rules (as Ganenkov 2018 did, when discussing Smith et al.'s (2018) analyses and other relevant data) or not (see also below). We could also discuss whether we want to call an instance of a morphologically conditioned phonological rule an irregularity in the language or not. What is clear to me, in any case, is that such data are relevant to Starke's project and deserve the nanosyntactian's attention and a true dialogue.

Let us go back to the initial question: "Should we try and find some sort of regularity?" Who is Starke's opponent here? Distributed Morphology? I personally do not know of a single person working in Distributed Morphology who is not looking for regularities and who proposed that memorising irregularities is the corner stone of the human linguistic competence. Admittedly, I do know analyses in Distributed Morphology in which patterns are ignored, but for good reason and after careful consideration. For example, Paster (2006) lists phonological insertion conditions on a vocabulary item, rather than assigning them to Phonology. She proposed to do so after careful empirical consideration in a study, that, note, tackles the challenging syntax-lexicon-phonology triangle. After having studied a wide array of data from many languages, she concluded that phonological insertion conditions are not always phonologically optimising. It is a reasonable assumption that phonology will not operate against its own interest and that some insertion conditions are indeed stored in Vocabulary. It follows from the way she organised the syntax-lexicon-phonology interfaces, that she proposed to store also other phonological insertion conditions which in fact are accidentally (?) optimising, thereby indeed ignoring patterns. Note that she does nothing more than allowing the storage of the unexpected in the lexicon. nanosyntax allows this as well, as we saw for French [se], sais, in the talk. Seriously considering lexical storage as an option is, in my opinion, reasonable when independently motivated, given what we know about human memory. 
Allow me to address the elephant in the room. Distributed Morphology has this post-syntactic module called Morphology which hosts a number of operations, including Fission (Noyer 1997), Impoverishment (Bonet 1991), and several Merge operations, including Morphological Merger (Marantz 1984), Syntactic Lowering (Bobaljik 1994) and Local Dislocation (Embick and Noyer 2001) and it has Vocabulary Insertion allowing for the insertion of underspecified vocabulary items, including zero affixes. Are the module of Morphology and the operation of Vocabulary Insertion the places where Distributed Morphology stopped looking for regularities? It is a question worth asking. In what follows I formulate three considerations.

Firstly, these morphologically operations were motivated empirically and if recent proposals adopt them, it is out of empirical concerns. We already saw an example above. If Ganenkov (2018) discusses readjustment rules, it is because he needs a solution for ABA-patterns. One could certainly criticise the tools, but the empirical concerns remain to be addressed.

Secondly, these operations are restricted and principled. Nevins (2007), for example, shows how Impoverishment is principally linked to markedness. The Subset Principle, for example, is a principle and it reflects the more general concept of the default. Starke argues that he does not postulate a superset principle anymore, but when I see that a vocabulary item that is associated with an overspecified phrase can be inserted, I do see a superset principle at work, albeit tacitly.

Thirdly, the current nanosyntactic approach should be compared to current work in Distributed Morphology. Older proposals from Distributed Morphology should be seen in their time. Consider, for example, readjustment rules. Readjustment rules go back to the hypothesis that the insertion of functional vocabulary items was regulated through the Subset Principle, whereas roots were inserted according to free choice (Harley and Noyer 1998). Marantz (1997) hypothesized that this distinction goes hand in hand with the distinction between true suppletion and morpho-phonological readjustment rules. It was hypothesized that true suppletion only applied to functional items and was regulated through the Subset Principle. Roots were assumed to be subject only to weak allomorphy, which was derived by the morpho-phonological readjustment rules. This dual insertion mechanism was given up in De Belder \& Van Craenenbroeck (2015). Harley (2014) falsified Marantz' (1997) hypothesis empirically (see also Veselinova 2006) and proposed that suppletive forms of roots compete for insertion as well. The insertion of the correct suppletive form depends on the syntactic context. Harley's (2014) proposal has gained a lot of consensus since its publication and the Roots IV workshop at the NYU (June 29 - July 2, 2015). Even before Harley (2014), the idea of readjustment rules had evolved into an indepth debate on how to model morpho-phonological rules that may apply to a language (see Trommer 2012 and the references mentioned in the previous section). It is completely acceptable for nanosyntax to hypothesize that morphophonological rules do not play a role in the human's linguistic competence, but to support such a hypothesis one will have to engage with a substantial body of recent work.

Take Fission as another example. It was formulated as a principle motivated by economy during language acquisition. The learner will prefer to 
assume fission in order to be able to use a sequence of already existing vocabulary items rather than to postulate a new vocabulary item (Noyer 1997, Halle 1997). Suppose the speaker has learned that morphemes with the feature set $\{a, b\}$ are realized as $/ \mathrm{i} /$ and those with the feature set $\{\mathrm{c}\}$ as $/ \mathrm{s} /$. Suppose further that the learner has independent evidence that the functional terminal node $\{a, b, c\}$ is indeed a single morpheme rather than a sequence of two separate ones (e.g., because of the number of specifiers). The learner will then prefer to analyze the string /is/ for the feature set $\{a, b, c\}$ as a composition of the exponents /i/ and /s/ rather than storing it as a new vocabulary item (see De Belder 2017:166 for discussion). I assume that this line of reasoning is not very different from what a nanosyntactic approach would find reasonable. Of course, the crucial difference lies in the fact that these approaches started with assuming bundles of features which then needed to be fissioned. Now, we all know why McGinnis in 1995 and both Noyer and Halle in 1997 did not adopt the idea not to bundle the features. The idea was only formulated by Starke in 2001! Looking back in 2021, not bundling the features when they will be realised by two separate affixes is, at least to my mind, the superior analysis. In fact, the fission data are important empirical finds that could now be read as data that even support the nanosyntax' nobundling hypothesis.

In conclusion, it is fair to approach all the morphological operations with some caution, but it is worth looking at the data and rationales that motivated them. They were often formulated to capture challenging and exciting data and a lot of work has been done to define these operations in a principled manner and to motivate them. Furthermore, a lot of work has been done since the nineties. It would be interesting to see a nanosyntactic project that truly engaged with the literature to show that it can capture the data in a more economical fashion.

\section{Conclusion}

To conclude, in their quest for 'regular morphology' the nanosyntactic proposals fully deserve the attention they are receiving as examples of proper morphological analysing. The nanosyntactic work impresses because of its exceptional coherence, empirical adequacy and minimal tools. Indeed, they offer tools and insights that allow us to find the regularity in inflectional chaos.

If we want to discuss the role of irregularities in morphology, we should include the following three elements in the discussion. Firstly, we should agree on a shared definition of the irregular. Secondly, we should acknowledge the role of the lexicon in nanosyntax as a storage for the irregular. Thirdly, we need to discuss why irregularities would be problematic to begin with.

One should also include more empirical domains. I would be most curious to learn how nanosyntax would approach lemma-creating morphology and the syntax-lexicon-phonology interfaces, domains where potential examples of the truly irregular can be found. These empirical domains are known to the field. In the $21^{\text {st }}$ century, Distributed Morphology has studied these interfaces and it has also included semantics in its studies. If nanosyntax would open a dialogue with more recent work in Distributed Morphology, this could be hugely beneficial to the field and, I believe, to its own project. 


\section{References}

Aitchison, Joan. 2012. Words in the Mind: An Introduction to the Mental Lexicon, 4th Edition. West-Sussex: Wiley-Blackwell.

Bobaljik, Jonathan. 1994. What does adjacency do? In H. Harley \& C. Philips (eds.) MITWPL 22: The Morphology-Syntax Connection, 1-32. Cambridge, MA: MITWPL.

Bonet, Eulàlia. 1991. Morphology after Syntax: Pronominal clitics in Romance. Doctoral Diss. MIT.

Bonet, Eulàlia \& Daniel Harbour. 2012. Contextual allomorphy. In J. Trommer (ed.), The morphology and phonology of exponence, 195-235. Oxford: Oxford University Press.

https://doi.org/10.1093/acprof:oso/9780199573721.003.0007

Booij, Geert. 1998. Prosodic output constraint in morphology. In W. Kehrein \& R. Wiese (eds.) Phonology and morphology of the Germanic languages, 143-163. Tübingen: Niemeyer.

https://doi.org/10.1017/s0022226799248049

Booij, Geert. 1999. The phonology of Dutch. Oxford: Oxford University Press.

Bye, Patrik. 2007. Allomorphy: selection, not optimization. In S. Blaho, P. Bye \& M. Krämer (eds.) Freedom of analysis? Studies in Generative Grammar, 63-92. Berlin: Mouton de Gruyter. https://doi.org/10.1515/9783110198591.63

Caha, Pavel. 2009. The nanosyntax of case. Doctoral diss., University of Troms $\varnothing$, Center for Advanced Study in Theoretical Linguistics.

Caha, Pavel, Karen De Clercq \& Guido Vanden Wyngaerd. 2019. The Fine Structure of the Comparative. Studia Linguistica, 73(3): 470-521.

https://doi.org/10.1111/stul.12107

Corver, Norbert. 2017. Adverbial -s: so awks but so natural! Ms., Utrecht University.

De Belder, Marijke. 2017. The root and nothing but the root: primary compounds in Dutch. Syntax. A journal of theoretical, experimental and interdisciplinary research 20(2): 138-169.

https://doi.org/10.1111/synt.12133

De Belder, Marijke. 2020. A split approach to the selection of allomorphs: vowel length alternating allomorphy in Dutch. Glossa: a journal of general linguistics 5(1): 42.

https://doi.org/10.5334/gjgl.899 
De Belder, Marijke. (to appear) The extravagant Dutch affix -ke and its meandering through the interfaces. In M. Eitelmann \& D. Haumann (eds.) Extravagant Morphology: Studies in rule-bending, pattern-extending and theorychallenging morphology. Studies in Language Companion Series. Amsterdam: John Benjamins Publishing Company.

De Belder, Marijke \& Jeroen Van Craenenbroeck. 2015. How to merge a root. Linguistic Inquiry 46:4: 625-655.

https://doi.org/10.1162/ling_a_00196

De Clercq, Karen. 2013. A unified syntax of negation. Doctoral diss., UGent.

Embick, David. 2010. Localism versus globalism in morphology and phonology (Linguistic Inquiry Monographs). Cambridge, MA: The MIT Press.

https://doi.org/10.1017/s0022226711000181

Embick, David \& Rolf Noyer. 2001. Movement operations after syntax. Linguistic Inquiry 32(4): 555-595.

https://doi.org/10.1162/002438901753373005

Ganenkov, Dmitry. 2018. The ABA pattern in Nakh-Daghestanian pronominal inflection. Snippets 34 Special Issue on Non-local Contextual Allomorphy.

https://doi.org/10.7358/snip-2018-034-gane

Halle, Morris. 1997. Distributed Morphology: Impoverishment and Fission. In B. Bruening, Y. Kang \& M. McGinnis. MITWPL 30 Papers at the Interface, 425449. Cambridge, MA: MITWPL.

Harley, Heidi. 2014. On the identity of roots. Theoretical Linguistics 40(3/4): 225-276.

DOI: $10.1515 /$ tl-2014-0010

Harley, Heidi \& Rolf Noyer. 1998. Licensing in the non-lexicalist lexicon: nominalizations, vocabulary items and the Encyclopaedia. In H. Harley (ed.) MITWP 32: Papers from the UPenn/MIT Roundtable on Argument Structure and Aspect, 119-137. Cambrdige, MA: MITWPL.

Lahiri, Aditi \& Bezalel Elan Dresher. 1999. Open syllable lengthening in West Germanic. Language 75(4): 678-719.

https://doi.org/10.2307/417730

Marantz, Alec. 1984. On the nature of grammatical relations. Cambridge, MA: The MIT Press.

Marantz, Alec. 1997. Stem suppletion, or the arbitrariness of the sign. Talk given at the Universite' de Paris VIII. 
McCarthy, John \& Alan Prince. 1993. Generalized alignment. In Geert Booij \& Jaap van Marle (eds.), Yearbook of Morphology 1993, 79-153. Dordrecht: Kluwer.

https://doi.org/10.1007/978-94-017-3712-8_4

McGinnis, Martha. 1995. Fission as feature-movement. In R. Pensalfini \& H. Ura (eds.) MITWPL 27 Papers on Minimalist Syntax, 165-187. Cambridge, MA: MITWPL.

Nevins, Andrew. 2007. Dual Number and Context-Sensitive Markedness. Ms. Harvard.

Nevins, Andrew. 2010. Phonologically-conditioned allomorph selection. In M. van Oostendorp, C. J. Ewen, E. Hume \& K. Rice (eds.) The Blackwell Companion to Phonology, 2357- 2382. Malden \& Oxford: Blackwell Publishing Ltd. https://doi.org/10.1017/s0952675713000079

Noyer, Rolf. 1997. Features, positions and affixes in autonomous morphological structure. New York: Garland Publishing.

Prokosch, Eduard 1939. A comparative Germanic grammar. Pennsylvania: Linguistic Society of America, University of Pennsylvania, Philadelphia.

Paster, Mary. 2006. Phonological conditions on affixation. Doctoral diss., University of California, Berkeley, CA.

Smith, Peter W., Beata Moskal, Ting Xu, Jungmin Kang \& Jonathan David Bobaljik. 2018. Case and Number Suppletion in Pronouns. Natural Language and Linguistic Theory 37(3): 1029-1101.

https://doi.org/10.1007/s11049-018-9425-0

Trommer, Jochen (ed.) 2012. The morphology and phonology of exponence. Oxford: Oxford University Press. https://doi.org/10.1017/s0022226713000406

Van der Hulst, Harry. 1985. Ambisyllabicity in Dutch. In H. Bennis \& F. Beukema (eds.). Linguistics in the Netherlands 1985, 57-67. Dordrecht: Foris. https://doi.org/10.1017/s0008413100012238

Veselinova, Ljuba N. 2006. Suppletion in verb paradigms: bits and pieces of the puzzle. Amsterdam: John Benjamins Publishing Co.

https://doi.org/10.1075/tsl.67

Wolf, Matthew Adam. 2008. Optimal interleaving: Serial phonology-morphology interaction in a constraint- based model. Doctoral diss., University of Massachusetts, Amherst, MA.

Yu, Alan C.L. 2003. The morphology and phonology of infixation. Doctoral diss., 
University of California, Berkeley, CA.

Zygis, Marzena. 2010. Typology of consonantal insertions. ZAS Papers in Linguistics 52: $111-140$.

https://doi.org/10.21248/zaspil.52.2010.385 